\title{
Prostate Cystadenoma
}

National Cancer Institute

\section{Source}

National Cancer Institute. Prostate Cystadenoma. NCI Thesaurus. Code C161606.

A rare cystadenoma affecting the prostate gland. It is characterized by the presence of multilocular prostatic cysts. 